\title{
Highly Chemo- and Stereoselective Transfer Semihydrogenation of Alkynes Catalyzed by a Stable, Well-Defined Manganese(II) Complex
}

\author{
Aleksandra Brzozowska, ${ }^{\ddagger}$ Luis Miguel Azofra, ${ }^{*}, \dagger \odot$ Viktoriia Zubar, ${ }^{\ddagger}$ Iuliana Atodiresei, ${ }^{\ddagger}$ Luigi Cavallo, ${ }^{\dagger}$

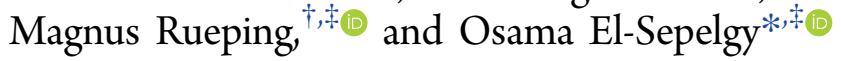

${ }^{*}$ Institute of Organic Chemistry, RWTH Aachen University, Landoltweg 1, 52074 Aachen, Germany

${ }^{\dagger}$ KAUST Catalysis Center, King Abdullah University of Science and Technology, Thuwal 23955-6900, Saudi Arabia

Supporting Information

ABSTRACT: Herein we report unprecedented manganesecatalyzed semihydrogenation of internal alkynes to $(Z)$-alkenes using ammonia borane as a hydrogen donor. The reaction is catalyzed by a pincer complex of the earth-abundant manganese(II) salt in the absence of any additives, base, or superhydride. The ammonia borane smoothly reduces the
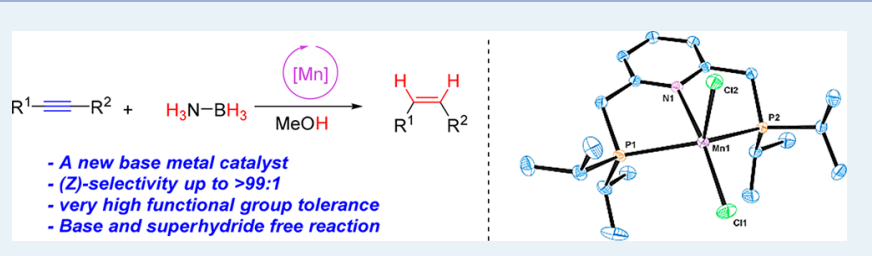
manganese precatalyst $[\mathrm{Mn}(\mathrm{II})-\mathrm{PNP}][\mathrm{Cl}]_{2}$ to the catalytically active species $[\mathrm{Mn}(\mathrm{I})-\mathrm{PNP}]$-hydride in the triplet spin state. This manganese hydride is highly stabilized by complexation with the alkyne substrate. Computational density functional theory (DFT) analysis studies of the reaction mechanism rationalize the origin of stereoselectivity toward formation of $(Z)$-alkenes.

KEYWORDS: base metals, manganese, pincer complexes, ammonia borane, alkynes, semihydrogenation

\section{INTRODUCTION}

Stereodefined alkenes are among the most important organic compounds, ubiquitous in chemical, material, and pharmaceutical industries. ${ }^{1}$ Semihydrogenation of alkynes to alkenes is a very important reaction in organic synthesis. ${ }^{2}$ Until today, triple-bond semireduction relies mainly on the use of precious metal catalysis. Among the known heterogeneous catalysts, the palladium-based Lindlar catalyst is the most prominent one. ${ }^{3}$ However, the necessity to use toxic lead salts as additive and the product isomerization under the reaction conditions are the major drawbacks of this method. Besides, various modern heterogeneous catalysts, ${ }^{4}$ homogeneous counterparts, such as the Rh-based Wilkinson's and Schrock-Osborn catalyst, ${ }^{5}$ palladium, ${ }^{6}$ ruthenium, ${ }^{7}$ and iridium ${ }^{8}$ catalysts have been intensively investigated for this reaction.

Economic and environmental aspects persuade chemists to replace toxic noble metal catalysts by first row base metal alternatives. In this regard, few homogeneous catalytic systems have been reported so far. In 2013, Srimani et al. have reported the use of acridine-based PNP iron catalyst for the $(Z)$-selective semihydrogenation of alkynes followed by rapid isomerization to $(E)$-alkenes under pressurized dihydrogen. ${ }^{9}$ More recently, processes relaying on the use of nickel, ${ }^{10}$ cobalt $^{11}$ and copper ${ }^{12}$ based catalysts have been disclosed. Nonetheless, these protocols may suffer from the use of high catalyst loading, limited substrate scope, and low levels of chemoselectivity or over-reduction. Despite these advances, new efficient catalytic systems based on earth-abundant metal catalysts would be highly desirable.

During the past months, manganese-catalyzed hydrogenation reactions have emerged. However, so far these are limited to the hydrogenation of $\mathrm{C}=\mathrm{O}$ and $\mathrm{C} \equiv \mathrm{N}$ bonds. ${ }^{13}$ To the best of our knowledge, a well-defined manganese complex catalyzing the (transfer) hydrogenation of unsaturated hydrocarbons has never been reported. Therefore, it was not surprising that our initial attempts to employ these complexes in semihydrogenation of alkynes were also unsuccessful.

The mechanism of the metal hydride catalyzed $(Z)$-selective semireduction of alkynes typically takes place via hydrometalation followed by reductive elimination steps, which requires a vacant coordination site on the metal center. However, the recently reported manganese hydrogenation catalysts are hexacoordinated pincer-Mn(I) complexes. Thus, in order to design a proper catalyst for this transformation, our attention was directed to the use of the five-coordinate manganese(II) dichloride, which after activation might be converted to tetracoordinate manganese(I) hydride. In contrast to the well-established iron(II) and cobalt(II) hydrogenation catalysts, manganese(II) dichloride has been reported to be inactive for the hydrogenation of carbonyl compounds. This might be attributed to the low stability of the formed $\mathrm{Mn}(\mathrm{I})$ hydride in the absence of carbonyl ligands. ${ }^{13 a, b}$

Ammonia borane $(\mathrm{AB})$ is a low molecular weight (30.87 $\mathrm{g}$ $\mathrm{mol}^{-1}$ ), bench-stable, inexpensive solid bearing both protic N$\mathrm{H}$ and hydric $\mathrm{B}-\mathrm{H}$ bonds. The good hydrogen capacity (16.9\% wt) and possibility of recycling its dehydrogenated products has inspired intensive studies toward the use of ammonia borane as $\mathrm{H}_{2}$ storage molecule. However, reports pertaining to the use of

Received: March 14, 2018

Revised: $\quad$ March 28, 2018

Published: March 30, 2018 
ammonia borane as a chemical reagent and, in particular, as hydrogen donor are scarce. ${ }^{14}$ We report herein the first example of manganese-catalyzed transfer hydrogenation of unsaturated carbon-carbon bonds using ammonia borane as an environmentally benign hydrogen donor (Scheme 1).

Scheme 1. Manganese-Catalyzed Transfer

Semihydrogenation of Alkynes

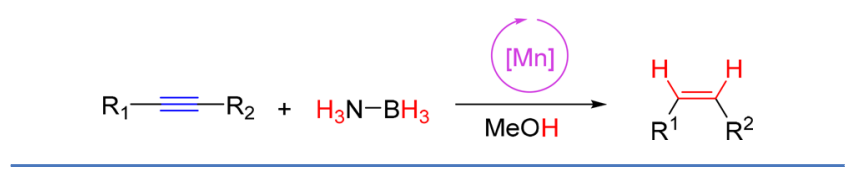

\section{RESULTS AND DISCUSSION}

We started our study with the synthesis of several PNP and NNN manganese pincer complexes (Mn-1-Mn-4, Figure 1).
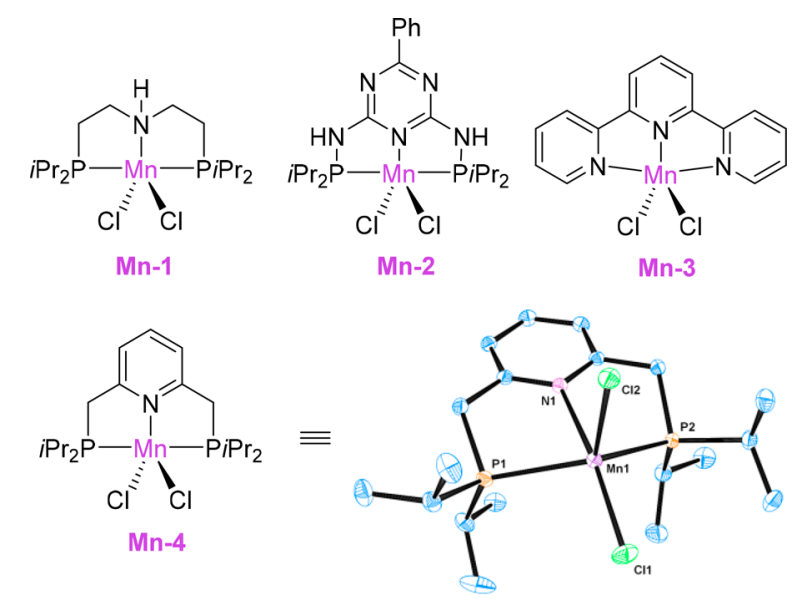

Figure 1. Manganese complexes tested in this study and X-ray crystal structure analysis of Mn-4 (hydrogen atoms omitted for clarity).

These five-coordinated Mn-complexes could be easily prepared by the reaction of the anhydrous manganese dichloride with 1.2 equiv of the corresponding ligand in THF at room temperature. The synthesis and the characterization of the complexes Mn-1 and $\mathbf{M n}-\mathbf{2}$ were recently reported by Elangovan et al. ${ }^{13 a}$ and Kallmeier et al., ${ }^{13 \mathrm{~b}}$ respectively. However, these complexes were inactive hydrogenation catalysts. Mn-3 was prepared from literature report. ${ }^{15}$ Furthermore, we have synthesized a new pyridine-based manganese complex $\mathbf{M n}-4$ in $80 \%$ yield. The crystal structure analysis of $\mathbf{M n}-\mathbf{4}$ showed that the coordination geometry of the manganese center is distorted square pyramidal (Figure 1).

Next, we investigated the catalytic activity of the manganese complexes Mn-1-Mn-4 in the hydrogenation of diphenylacetylene (1a) as a model substrate. Methanol was used as a solvent and ammonia borane as both the potential catalyst activator and hydrogen donor. The NH-based PNP manganese complex Mn-1 provided only low conversion (27\%) with 84:16 $Z / E$ ratio (Table 1 , entry 1 ). Higher yield (69\%) and a slightly higher $Z / E$ ratio $(88: 12)$ were observed by the application of triazine-based PNP-manganese complex Mn-2 (Table 1, entry 2). Subsequently, we tested the catalytic performance of the readily available terpyridine- $\mathrm{Mn}$ (II) complex $\mathbf{M n - 3}$; however, only moderate results were obtained (Table 1 , entry 3 ). To our delight, the newly synthesized pyridyl-based PNP complex Mn4 showed full conversion and very good selectivity (97:3, Table
Table 1. Optimization of the Reaction Conditions ${ }^{a}$

\begin{tabular}{|c|c|c|c|c|}
\hline $\begin{array}{r}\mathrm{Ph}-\overline{=} \\
1 \mathrm{a}\end{array}$ & $-\mathrm{Ph}+\mathrm{NH}_{3}-\mathrm{BH}_{3}$ & $\begin{array}{c}\begin{array}{c}{[\mathrm{Mn}]} \\
\text { solvent }\end{array} \\
60^{\circ} \mathrm{C}, 16 \mathrm{~h}\end{array}$ & $\mathrm{Ph}_{2 \mathrm{a}}^{\mathrm{H}} \mathrm{Ph}_{\mathrm{Ph}}^{\mathrm{H}}+$ & $\left.{ }_{3 a}\right\}^{P h}$ \\
\hline entry & {$[\mathrm{Mn}](\mathrm{mol} \%)$} & solvent & conversion (\%) & 2a:3a \\
\hline 1 & Mn-1 (2) & $\mathrm{MeOH}$ & 27 & $84: 16$ \\
\hline 2 & Mn-2 (2) & $\mathrm{MeOH}$ & 69 & $88: 12$ \\
\hline 3 & Mn-3 (2) & $\mathrm{MeOH}$ & 62 & $79: 21$ \\
\hline 4 & Mn-4 (2) & $\mathrm{MeOH}$ & $>99$ & $97: 03$ \\
\hline 5 & $\mathrm{MnCl}_{2}(2)$ & $\mathrm{MeOH}$ & 29 & $78: 22$ \\
\hline 6 & Mn-4 (2) & $\mathrm{EtOH}$ & 99 & $85: 15$ \\
\hline 7 & Mn-4 (2) & $i-\mathrm{PrOH}$ & 41 & $95: 05$ \\
\hline 8 & Mn-4 (2) & HFIP & 06 & ND \\
\hline 9 & Mn-4 (2) & TFE & 08 & ND \\
\hline 10 & Mn-4 (2) & THF & 87 & $72: 28$ \\
\hline 11 & Mn-4 (2) & dioxane & 63 & $79: 21$ \\
\hline 12 & Mn-4 (2) & DMF & 14 & $80: 20$ \\
\hline 13 & Mn-4 (2) & NMP & 21 & $83: 17$ \\
\hline 14 & Mn-4 (2) & toluene & 14 & $83: 17$ \\
\hline 15 & Mn-4 (2) & hexane & $<5$ & ND \\
\hline $16^{b}$ & Mn-4 (2) & $\mathrm{MeOH}$ & $<5$ & ND \\
\hline $17^{c}$ & Mn-4 (2) & $\mathrm{MeOH}$ & $<5$ & ND \\
\hline 18 & Mn-4 (1) & $\mathrm{MeOH}$ & $>99$ & $99: 01$ \\
\hline 19 & Mn-4 (0.5) & $\mathrm{MeOH}$ & 76 & $95: 05$ \\
\hline
\end{tabular}

${ }^{a}$ Reaction conditions: $\mathbf{1}(0.25 \mathrm{mmol}), \mathrm{AB}(0.25 \mathrm{mmol}), \mathbf{M n}$ catalyst in $1 \mathrm{~mL}$ of solvent at $60{ }^{\circ} \mathrm{C}$ for $16 \mathrm{~h}$. Conversion was determined by ${ }^{1} \mathrm{H}$ NMR using mesitylene as the internal standard. $Z / E$ ratio was determined by GC analysis. ${ }^{b} \mathrm{AB}(0.025 \mathrm{mmol}), \mathrm{H}_{2}$ (10 bar). ${ }^{c} \mathrm{AB}$ $(0.025 \mathrm{mmol}), \mathrm{HCOOH}(0.5 \mathrm{mmol})$.

1, entry 4). The use of $\mathrm{MnCl}_{2}$ as a catalyst afforded low conversion and selectivity (Table 1 , entry 5 ), highlighting the crucial role of the ligand.

Next, different solvents were tested. Replacing $\mathrm{MeOH}$ by $\mathrm{EtOH}$ resulted in the same conversion but lower $Z / E$ ratio (Table 1, entry 6). The promising results in methanol and ethanol have encouraged us to investigate more alcohols such as $i-\mathrm{PrOH}$ and more acidic fluorinated solvents: trifluoroethanol (TFE) and hexafluoroisopropyl alcohol (HFIP). However, these alcohols proved to be unsuitable for this reaction (Table 1 , entries 7-9). Interestingly, running the reaction in THF or dioxane afforded moderate results (Table 1, entries 10-11). Furthermore, reactions performed in DMF or NMP led to very low conversions, probably due to the strong coordination of these solvents with the catalyst (Table 1, entries 12-13). The solvent screening shows that the nonpolar solvents hexane and toluene failed to give the desired product (Table 1, entries 1415).

Moreover, in order to exclude molecular hydrogen as a reactant in the described process, the reaction was examined under hydrogen atmosphere (10 bar) in the presence of catalytic amounts of $A B$. Importantly, only traces of the desired product were detected (Table 1, entry 16). This result suggests that the reaction takes place via direct transfer hydrogenation and not via $\mathrm{AB}$ solvolysis followed by hydrogenation. Also, formic acid has been demonstrated to be an unsuitable hydrogen donor in this process (Table 1, entry 17).

Following these results, we turned our attention to screening of the reaction conditions with the respect to the catalyst loading (Mn-4). Pleasingly, the reaction still proceeded well with a catalyst loading as low as $1 \mathrm{~mol} \%$ (Table 1 , entry 18). 
Subsequent reduction of the catalyst to $0.5 \mathrm{~mol} \%$ resulted in lower conversion of $76 \%$ after $16 \mathrm{~h}$ (Table 1 , entry 19 ).

In order to demonstrate the applicability of our manganese catalyst system, we tested the transfer hydrogenation of various internal alkyne substrates bearing different electronic and steric properties (Table 2). Generally, all investigated aromatic

Table 2. Manganese-Catalyzed ( $Z$ )-Selective Transfer Hydrogenation of Alkynes ${ }^{a}$

$$
\mathrm{R}^{1}=\mathrm{R}^{2}+\mathrm{NH}_{3}-\mathrm{BH}_{3} \frac{\mathrm{Mn}-4}{\mathrm{MeOH}, 60-70^{\circ} \mathrm{C},} \underset{\mathrm{R}^{1}}{\longrightarrow} \mathrm{R}_{\mathrm{R}^{2}}
$$

$20 \mathrm{~h}$

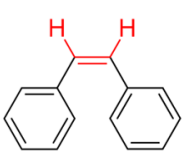

2a

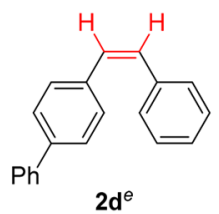

$94 \%,>99$ Z/E

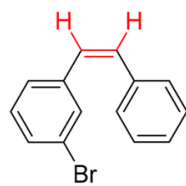

$2 \mathrm{~g}^{b, f, i}$

90\%, 93:7 Z/E

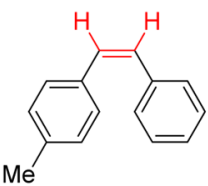

2j

$90 \%, 97: 3$ Z/E

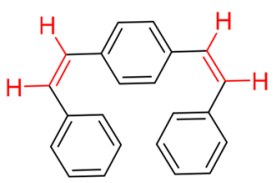

$2 \mathbf{m}^{d, f}$

84\%, 93:7 Z/E

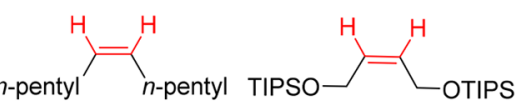

$\mathbf{2 p}^{d, h, i}$
$52 \%,>99: 1 Z$

$2 \mathbf{q}^{b, f, i} 81 \%$
91\%, 99:1 ZIE

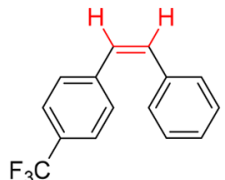

2b

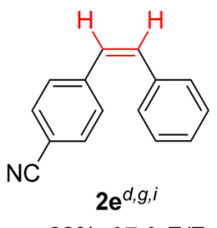

$82 \%, 97: 3 \mathrm{Z} / E$

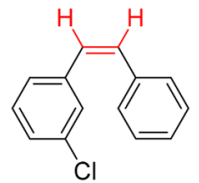

$\mathbf{2 h}^{b, f, i}$

$$
\text { 89\%, 99:1 Z/E }
$$

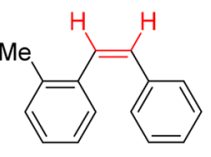

$\mathbf{2 k}^{b, e}$

93\%, 98:2 Z/E

$2 \mathbf{n}^{c, f, i}$

48\%, 98:2 Z/E

88:12 Z/E
$93 \%,>99: 1$ ZIE

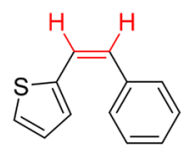

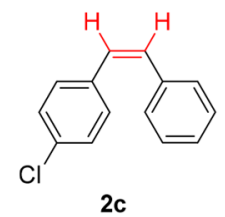

$98 \%, 95: 5$ ZIE
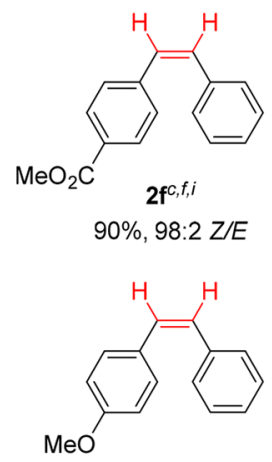

2i

86\%, 95:5 Z/E

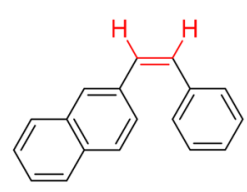

$21^{b, e, i}$

82\%, 99:1 Z/E

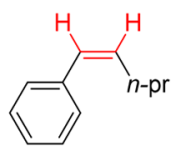

$\mathbf{2 o}^{c, f, i}$

$67 \%,>99: 1$ Z/E

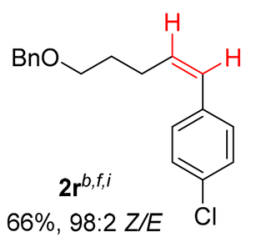

${ }^{a}$ Reaction conditions: 1 (0.5 mmol), AB (0.5 mmol), Mn-4 (1 mol \%) in $2 \mathrm{~mL}$ of methanol at $60{ }^{\circ} \mathrm{C}$ for $20 \mathrm{~h}$, yields after column chromatography, $Z / E$ ratio is determined by $\mathrm{GC}$ analysis of the crude reaction mixture. ${ }^{b}$ Mn-4 (2 mol \%). ${ }^{c}$ Mn-4 (3 mol \%). ${ }^{d}$ Mn-4 (4 mol \%). ${ }^{e} \mathrm{AB}$ (0.75 mmol). ${ }^{f} \mathrm{AB}$ (1 mmol). ${ }^{g} \mathrm{AB}$ (1.5 mmol). ${ }^{h} \mathrm{AB}(2$ $\mathrm{mmol}) .{ }^{i} 70{ }^{\circ} \mathrm{C}$. substrates with electron-withdrawing groups and electrondonating groups were converted into the corresponding $(Z)$ alkenes with very good yields and excellent $(Z):(E)$ selectivity 1a-1n. Interestingly, sensitive functional groups such as nitrile, ester, and heterocycles were well-tolerated under the mild reaction conditions. The semitransfer hydrogenation could also be applied to the mono- and dialkylacetylene 10 and $1 \mathbf{p}$ after using more catalyst loading and ammonia borane. The protected allyl alcohol $\mathbf{2 q}$ could be obtained in $81 \%$ yield and good selectivity. Finally, the pentynol-derived alkyne 1r could be selectively semihydrogenated in good yield (66\%).

Apart from the synthetic value of the conversion of alkynes to alkenes, we decided to investigate the application of the newly developed catalytic system in the purification of alkenes from alkyne impurities, which is a highly important industrial process to valorize the steam cracking bulk feedstocks. ${ }^{4 g}$ To demonstrate the process feasibility, we hydrogenated diphenylacetylene in the presence of a large excess of $(Z)$-stilbene. To our delight, $0.03 \mathrm{mmol}$ of diphenylacetylene could be hydrogenated in the presence 100 equiv of $(Z)$-stilbene using only $0.0003 \mathrm{mmol}$ of the Mn-4. Importantly, $(Z)$-alkenes were obtained with $99 \%$ purity with only traces of the isomerized $(E)$-alkene $3 \mathbf{a}$ and no overhydrogenation product was detected (Scheme 2).

Scheme 2. Showcase of Manganese-Catalyzed Purification of Cis Alkenes without Isomerization

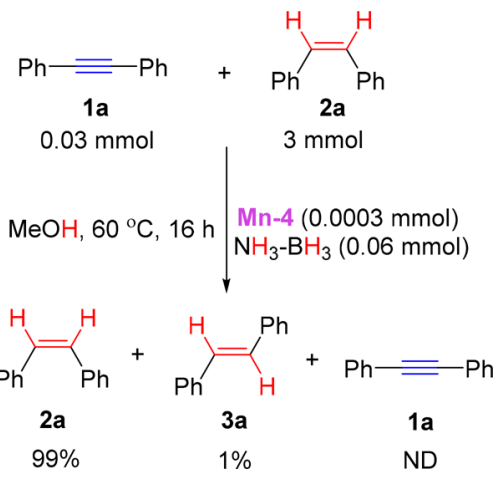

With this background knowledge we studied the reaction mechanism for diphenylacetylene reduction into stilbene through density functional theory (DFT) modeling (Figure 2). ${ }^{17}$ Gibbs free reaction and activation energies were calculated at $50{ }^{\circ} \mathrm{C}$ in methanol as a solvent. The precatalyst we considered is Mn-4, which we suggest can be reduced into the active catalytic $[\mathrm{Mn}(\mathrm{I})-\mathrm{PNP}]$-hydride species (A, at Figure 2) by $\mathrm{NH}_{3} \mathrm{BH}_{3}$. This hypothesis is based on the consideration that thermogravimetric analysis and differential scanning calorimetric studies proved that $\mathrm{CoCl}_{2}$ to be reduced into cobalt(I) by induction of $\mathrm{NH}_{3} \mathrm{BH}_{3}$ decomposition. These findings served as the basis for demonstrating the reducing power of $\mathrm{NH}_{3} \mathrm{BH}_{3}$ toward other compounds such as $\mathrm{FeCl}_{3}$ and $\mathrm{AlCl}_{3}$ species. ${ }^{16}$ Starting from the proposed active species A, two catalytic cycles working simultaneously can be proposed to explain the product distribution. One is the alkyne reduction cycle, converting diphenylacetylene into $(Z)$-stilbene; the second is the alkene isomerization cycle, converting $(Z)$-stilbene into $(E)$-stilbene.

Calculations indicate that the reaction occurs through a triplet state spin route (Table S1). For example, in the case of the catalytic species $\mathbf{A}$ the triplet spin state is more stable than the singlet spin state by 27.5 and $32.4 \mathrm{kcal} \mathrm{mol}^{-1}$ at the PBE/ 


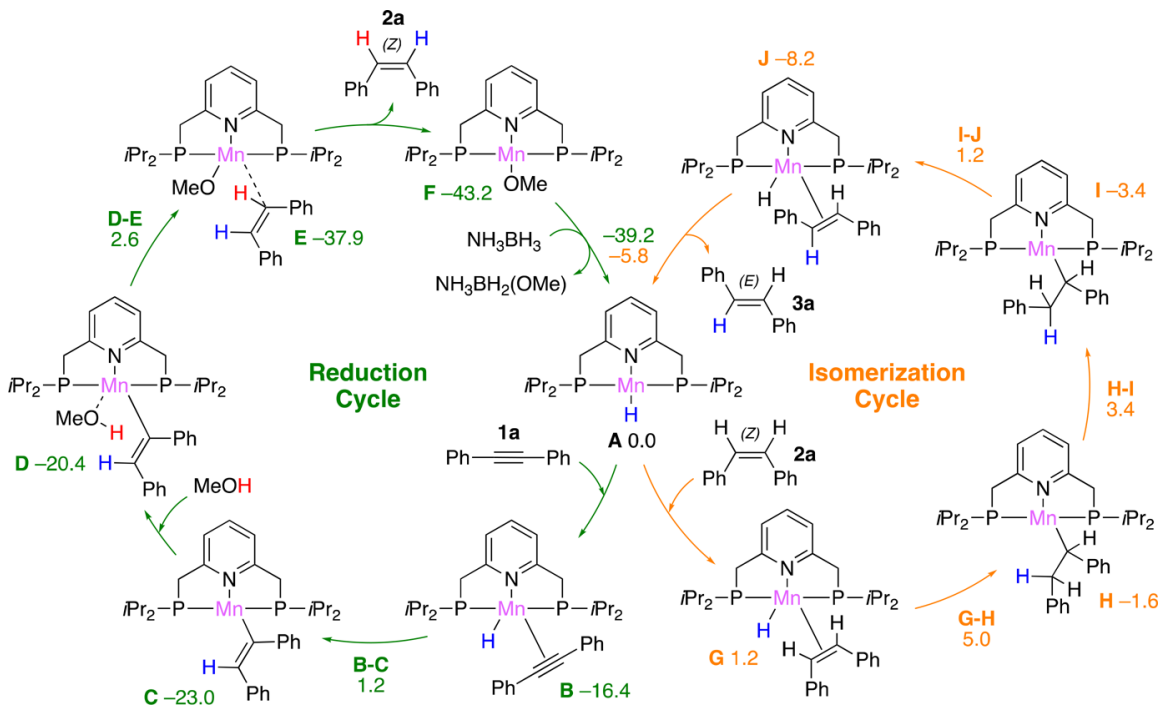

Figure 2. Proposed reaction mechanism for manganese-catalyzed semitransfer hydrogenation of diphenylacetylene (1a) into $(Z)$-stilbene (2a) (reduction cycle) and internal conversion of $(Z)$-stilbene $(\mathbf{2 a})$ into $(E)$-stilbene (3a) (isomerization cycle). Calculated Gibbs free reaction and activation energies, at $50{ }^{\circ} \mathrm{C}$, are shown in $\mathrm{kcal} \mathrm{mol}^{-1}$ at the PBE0+D3(BJ)/TZVP//PVE/SVP computational level in methanol as solvent.

SVP and PBE0+D3(BJ)/TZVP//PVE/SVP levels of theory in methanol. These values are consistent with the value of 33.5 $\mathrm{kcal} \mathrm{mol}^{-1}$ calculated at the OPBE/SVP level in the gas phase. ${ }^{18}$

The alkyne reduction cycle, converting diphenylacetylene into $(Z)$-stilbene, starts with coordination of diphenylacetylene to the $[\mathrm{Mn}(\mathrm{I})-\mathrm{PNP}]$-hydride catalyst $\mathbf{A}$, spontaneously forming the stable complex $\mathbf{B}$, with a binding Gibbs free energy at $50{ }^{\circ} \mathrm{C}$ of $-16.4 \mathrm{kcal} \mathrm{mol}^{-1}$ in methanol. The overall structure of B (see Figure S2) has a strong metallacycloolefin character, as the $\mathrm{C}-\mathrm{C}-\mathrm{Ph}$ angles are severely bent from $180^{\circ}$ in the isolated substrate, to assume an average value of $143^{\circ}$. The C-C bond, $1.34 \AA$, is close to the value of $1.36 \AA$ as in the isolated (Z)-stilbene, compared to $1.23 \AA$ in the isolated diphenylacetylene.

This first hydrogenation of the substrate, leading to intermediate $\mathbf{C}$, exhibits a Gibbs free activation energy of $17.6 \mathrm{kcal} \mathrm{mol}^{-1}$ via transition state $\mathbf{B}-\mathbf{C}$. Intermediate $\mathbf{C}$ presents a cis disposition of the $\mathrm{Ph}$ substituents on the formed $\mathrm{C}=\mathrm{C}$ double bond. The overall skeleton of the reacting carbonaceous moiety is perpendicular to the PNP plane, see Figure 3. The formed $\mathrm{Mn}-\mathrm{C}$ bond is nearly collinear with the $\mathrm{Mn}-\mathrm{N}$ bond, with a $\mathrm{Mn}-\mathrm{N}-\mathrm{C}$ angle of $161^{\circ}$, and the large distance between $\mathrm{Mn}$ and the transferred $\mathrm{H}$ atom, $3.17 \AA$, indicates no agostic interaction.

The next step corresponds to $\mathrm{MeOH}$ interaction with the $\mathrm{Mn}$ center, leading to intermediate $\mathrm{D}$, with a free energy increasing in $2.6 \mathrm{kcal} \mathrm{mol}^{-1}$. The long distance between the $\mathrm{Mn}$ and the $\mathrm{O}$ atom of $\mathrm{MeOH}, 3.60 \AA$, suggests this interaction being dominated by dispersion forces. Indeed, the enthalpy of association (between $\mathrm{MeOH}$ and $\mathbf{C}$ to reach $\mathbf{D}$ ) at the PBE0/ TZVP//PVE/SVP level amounts to $-6.6 \mathrm{kcal} \mathrm{mol}^{-1}$, while at the $\mathrm{PBE} 0+\mathrm{D} 3(\mathrm{BJ}) / \mathrm{TZVP} / / \mathrm{PVE} / \mathrm{SVP}$ level, which is after addition of an empirical dispersion term, it amounts to -11.1 $\mathrm{kcal} \mathrm{mol}^{-1}$. Proton transfer from $\mathrm{MeOH}$ to the substrate occurs via transition state $\mathbf{D}-\mathbf{E}$, indicated to be the rate-limiting step with a relative activation Gibbs free energy of $25.6 \mathrm{kcal} \mathrm{mol}^{-1}$ (energy span from $\mathbf{C}$ to $\mathbf{D}-\mathbf{E}$ ). Once $(Z$ )-stilbene is released in a spontaneous process, the formed $[\mathrm{Mn}]-\mathrm{OMe}$ intermediate $\mathbf{F}$ reacts with $\mathrm{NH}_{3} \mathrm{BH}_{3}$ to regenerate the starting $[\mathrm{Mn}(\mathrm{I})-\mathrm{PNP}]-$ hydride catalytic species $\mathbf{A}$.

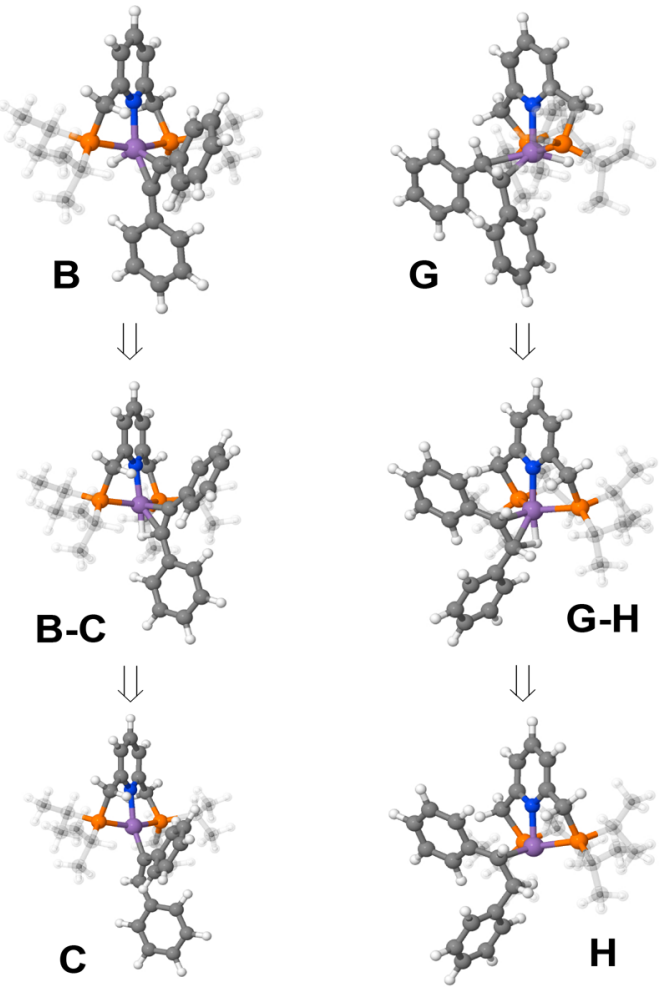

Figure 3. Minima and transition states for the hydride transfer steps in the reduction $(\mathrm{B}-\mathrm{C})$ and isomerization $(\mathrm{G}-\mathrm{H})$ cycles. (For clarity, $i$ $\mathrm{Pr}_{2}$ groups are in soft color.)

A key feature of the above reaction pathway is that the initial hydrogen transfer to diphenylacetylene, step $\mathbf{B}$ to $\mathbf{C}$, occurs with formation of a $\mathrm{Mn}$-vinyl bond presenting a cis disposition of the $\mathrm{Ph}$ substituents. Since no free rotation around the $\mathrm{C}=\mathrm{C}$ double bond of the substrate is possible, stereoselectivity toward the $(Z)$-alkene is imposed. Our attempts to locate an alternative transition state in which proton transfer from an external $\mathrm{MeOH}$ to diphenylacetylene occurs first followed by the hydride transfer from the $\mathrm{Mn}-\mathrm{H}$ moiety failed. 
Furthermore, the potential role of $\mathrm{NH}_{3} \mathrm{BH}_{3}$ as proton donor instead of $\mathrm{MeOH}$ during the $\mathbf{D}^{\prime}$ to $\mathbf{E}^{\prime}$ step has been also investigated. The large activation Gibbs free energy of $37.1 \mathrm{kcal}$ $\mathrm{mol}^{-1}$ (relative to $\mathrm{C}$ ) clearly rules out this route in the presence of $\mathrm{MeOH}$ (Figure S3). Finally, we also analyzed both the reduction and isomerization cycles in THF, where $\mathrm{NH}_{3} \mathrm{BH}_{3}$ is the sole source of proton (see Figure S4). Proton transfer from $\mathrm{NH}_{3} \mathrm{BH}_{3}$ to the substrate via transition state $\mathbf{D}^{\prime}-\mathbf{E}^{\prime}$, with a Gibbs free energy of activation of $35.5 \mathrm{kcal} \mathrm{mol}^{-1}$, is again of high energy, which depresses reactivity. These results are in agreement with experimental solvent screening experiments in Table 1.

The formation of $(E)$-stilbene may also be explained via the alkene isomerization cycle shown in Figure 2. Within this cycle the catalytic species $\mathbf{A}$ interacts with $(Z)$-stilbene leading to complex G. This is a slightly endergonic step, with a binding Gibbs free energy of $1.2 \mathrm{kcal} \mathrm{mol}^{-1}$, which contrasts with the large binding energy of diphenylacetylene to A (-16.4 kcal $\mathrm{mol}^{-1}$ ). Hydride transfer from $\mathrm{Mn}(\mathrm{I})$ of $\mathbf{G}$ to the closest $\mathrm{C}$ atom of stilbene leads to intermediate $\mathbf{H}$. This hydrogenation transfer exhibits a low relative activation barrier of $5.0 \mathrm{kcal}$ $\mathrm{mol}^{-1}$ and leads to an $\mathrm{sp}^{3}$ hybridization of the $\mathrm{C}$ atom of stilbene, which indeed allows easy rotation around the $\mathrm{C}-\mathrm{C}$ bond, step $\mathbf{H}$ to $\mathbf{I}$ (the relative rotational activation barrier is calculated to be $\left.5.0 \mathrm{kcal} \mathrm{mol}^{-1}\right) . \beta-\mathrm{H}$ transfer to the $\mathrm{Mn}$ atom from $\mathbf{I}$ via transition state $\mathbf{I}-\mathbf{J}$ with Gibbs free energy barrier of $4.6 \mathrm{kcal} \mathrm{mol}^{-1}$ leads to (E)-stilbene, intermediate J. Finally, dissociation of $(E)$-stilbene from the metal regenerates the catalytic species $\mathbf{A}$.

Comparison between the reduction and the isomerization cycles shows that coordination of diphenylacetylene to the catalytic species $\mathbf{A}$ is favored by $17.6 \mathrm{kcal} \mathrm{mol}^{-1}$ over $(Z)$ stilbene coordination $\left(-16.4 \mathrm{vs} 1.2 \mathrm{kcal} \mathrm{mol}^{-1}\right)$. Steric effects play a minor role in determining this large difference in the binding energies, as a similarly large difference, $14.0 \mathrm{kcal} \mathrm{mol}^{-1}$, is calculated for coordination of diphenylacetylene and $(Z)$ stilbene to a model system where the $i$-Pr substituents on the $\mathrm{P}$ atoms of PNP ligands are replaced by smaller methyl groups, -17.3 and $-3.3 \mathrm{kcal} \mathrm{mol}^{-1}$, respectively. Further, coordination of the simplest alkyne (acetylene) and alkene (ethylene) to this model system with methyl substituents on the $\mathrm{P}$ atoms displays again a large difference in the binding Gibbs free energies, -18.3 and $-7.8 \mathrm{kcal} \mathrm{mol}^{-1}$, confirming that preferential alkyne coordination over alkene coordination is dominated by electronic effects.

Considering that the substrate-coordinated intermediates $\mathbf{B}$ and $\mathbf{G}$ are connected by intermediate $\mathbf{A}$, the Curtin-Hammett principle can be used to relate the faster kinetics of the alkyne reduction cycle to the energy difference between the highestlaying transition states along the two cycles, which is transition states $\mathbf{D}-\mathbf{E}$ and $\mathbf{G}-\mathbf{H}$. Consistent with the experimental evidence, the former, along the alkyne reduction cycle, is favored by $2.4 \mathrm{kcal} \mathrm{mol}^{-1}$ over the latter, taking place along the alkene isomerization cycle.

\section{CONCLUSIONS}

A new manganese-catalyzed hydrogenation of unsaturated hydrocarbons is reported herein. ${ }^{9}$ Notably, the newly developed catalytic system is based on an earth-abundant metal which is shown to be highly active for semitransfer hydrogenation of internal alkynes under base- and superhydride-free conditions. Ammonia borane was used as both potential hydrogen donor and catalyst activator. Under mild conditions a broad scope of internal alkynes bearing different functional groups are converted to $(Z)$-alkenes in up to $98 \%$ yield and >99:1 (Z):(E) selectivity. Importantly, this base metal catalyst allows for the purification of alkenes from alkyne impurities without alkene isomerization. The ammonia borane smoothly reduces the manganese precatalyst $[\mathrm{Mn}(\mathrm{II})-\mathrm{PNP}]$ $[\mathrm{Cl}]_{2}$ to the active catalytic species $[\mathrm{Mn}(\mathrm{I})-\mathrm{PNP}]$-hydride in the triplet spin state which is highly stabilized by the complexation with the alkyne substrate. DFT calculations indicate that two catalytic cycles, one for hydrogenation of diphenylacetylene to $(Z)$-stilbene (the reduction cycle), the other for isomerization of $(Z)$ to $(E)$-stilbene (the isomerization cycle), are in competition. The strong thermodynamics control imposed during the early catalyst $\cdots$ substrate coordination steps explains the selectivity showed by the $[\mathrm{Mn}(\mathrm{I})-$ PNP]-hydride species for the preferred reduction of diphenylacetylene into $(Z)$-stilbene over the $(E)$ isomer.

\section{ASSOCIATED CONTENT}

Supporting Information

The Supporting Information is available free of charge on the ACS Publications website at DOI: 10.1021/acscatal.8b00983.

Experimental and DFT details, and cartesian coordinates (PDF)

Crystallographic data (CIF)

\section{AUTHOR INFORMATION}

\section{Corresponding Authors}

*E-mail: luis.azoframesa@kaust.edu.sa.

*E-mail: Osama.Elsepelgy@rwth-aachen.de.

ORCID 을

Luis Miguel Azofra: 0000-0003-4974-1670

Luigi Cavallo: 0000-0002-1398-338X

Magnus Rueping: 0000-0003-4580-5227

Osama El-Sepelgy: 0000-0003-3131-4988

Notes

The authors declare no competing financial interest.

\section{ACKNOWLEDGMENTS}

L.M.A. and L.C. acknowledge King Abdullah University of Science and Technology (KAUST) for support. Gratitude is also due to the KAUST Supercomputing Laboratory using the supercomputer Shaheen II for providing the computational resources.

\section{REFERENCES}

(1) Williams, J. M. J. Preparation of Alkenes: A Practical Approach; Oxford University Press: Oxford, U.K., 1996.

(2) (a) Oger, C.; Balas, L.; Durand, T.; Galano, J.-M. Are Alkyne Reductions Chemo-, Regio-, and Stereoselective Enough To Provide Pure $(Z)$-Olefins in Polyfunctionalized Bioactive Molecules? Chem. Rev. 2013, 113, 1313-1350. (b) Rylander, P. N. Catalytic Hydrogenation in Organic Syntheses; Academic Press: New York, 1979. (c) De Vries, J. G.; Elsevier, C. J. Handbook of Homogeneous Hydrogenation; Wiley-VCH: Weinheim, Germany, 2007. (d) Andersson, P. G.; Munslow, I. J. Modern Reduction Methods; Wiley: New York, 2008.

(3) (a) Lindlar, H. Ein neuer Katalysator für selektive Hydrierungen. Helv. Chim. Acta 1952, 35, 446-450. (b) Lindlar, H.; Dubuis, R. Palladium catalyst for partial reduction of acetylenes. Org. Synth. 1966, $46,89$.

(4) For selected examples of semihydrogenation of alkynes using heterogeneous catalysts see: (a) Mitsudome, T.; Takahashi, Y.; Ichikawa, S.; Mizugaki, T.; Jitsukawa, K.; Kaneda, K. Metal-Ligand 
Core-Shell Nanocomposite Catalysts for the Selective Semihydrogenation of Alkynes. Angew. Chem., Int. Ed. 2013, 52, 1481-1485. (b) Gieshoff, T. N.; Welther, A.; Kessler, M. T.; Prechtl, M. H. G.; Jacobi von Wangelin, A. Stereoselective Iron-Catalyzed Alkyne Hydrogenation in Ionic Liquids. Chem. Commun. 2014, 50, 22612264. (c) Karunananda, M. K.; Mankad, N. P. E-Selective SemiHydrogenation of Alkynes by Heterobimetallic Catalysis. J. Am. Chem. Soc. 2015, 137, 14598-14601. (d) Mitsudome, T.; Yamamoto, M.; Maeno, Z.; Mizugaki, T.; Jitsukawa, K.; Kaneda, K. One-step Synthesis of Core-Gold/Shell-Ceria Nanomaterial and Its Catalysis for Highly Selective Semihydrogenation of Alkynes. J. Am. Chem. Soc. 2015, 137, 13452-13455. (e) Vasilikogiannaki, E.; Titilas, I.; Vassilikogiannakis, G.; Stratakis, M. Cis-Semihydrogenation of Alkynes with Amine Borane Complexes Catalyzed by Gold Nanoparticles under Mild Conditions. Chem. Commun. 2015, 51, 2384-2387. (f) Konnerth, H.; Prechtl, M. H. G. Selective Partial Hydrogenation of Alkynes To $(Z)$ Alkenes with Ionic Liquid-Doped Nickel Nanocatalysts at Near Ambient Conditions. Chem. Commun. 2016, 52, 9129-9132. (g) Chen, F.; Kreyenschulte, C.; Radnik, J.; Lund, H.; Surkus, A.-E.; Junge, K.; Beller, M. Selective Semihydrogenation of Alkynes with NGraphitic-Modified Cobalt Nanoparticles Supported on Silica. ACS Catal. 2017, 7, 1526-1532. (h) Lu, Y.; Feng, X.; Takale, B. S.; Yamamoto, Y.; Zhang, W.; Bao, M. Highly Selective Semihydrogenation of Alkynes to Alkenes by Using an Unsupported Nanoporous Palladium Catalyst: No Leaching of Palladium into the Reaction Mixture. ACS Catal. 2017, 7, 8296-8303.

(5) (a) Osborn, J. A.; Jardine, F. H.; Young, J. F.; Wilkinson, G. The Preparation and Properties of Tris(Triphenylphosphine)Halogenorhodium(I) and Some Reactions Thereof Including Catalytic Homogeneous Hydrogenation of Olefins and Acetylenes and Their Derivatives. J. Chem. Soc. A 1966, 1711-1732. (b) Schrock, R. R.; Osborn, J. A. Catalytic Hydrogenation Using Cationic Rhodium Complexes. I. Evolution of the Catalytic System and the Hydrogenation of Olefins. J. Am. Chem. Soc. 1976, 98, 2134-2143.

(6) (a) van Laren, M. W.; Elsevier, C. J. Selective Homogeneous Palladium(0)-Catalyzed Hydrogenation of Alkynes to (Z)-Alkenes. Angew. Chem., Int. Ed. 1999, 38, 3715-3717. (b) Shen, R.; Chen, T.; Zhao, Y.; Qiu, R.; Zhou, Y.; Yin, S.; Wang, X.; Goto, M.; Han, L.-B. Facile Regio- and Stereoselective Hydrometalation of Alkynes with a Combination of Carboxylic Acids and Group 10 Transition Metal Complexes: Selective Hydrogenation of Alkynes with Formic Acid. J. Am. Chem. Soc. 2011, 133, 17037-17044. (c) Drost, R. M.; Bouwens, T.; van Leest, N. P.; de Bruin, B.; Elsevier, C. J. Convenient Transfer Semihydrogenation Methodology for Alkynes Using a Pd(II)-NHC Precatalyst. ACS Catal. 2014, 4, 1349-1357.

(7) (a) Radkowski, K.; Sundararaju, B.; Fürstner, A. A FunctionalGroup-Tolerant Catalytic trans Hydrogenation of Alkynes. Angew. Chem., Int. Ed. 2013, 52, 355-360. (b) Leutzsch, M.; Wolf, L. M.; Gupta, P.; Fuchs, M.; Thiel, W.; Farès, C.; Fürstner, A. Formation of Ruthenium Carbenes by gem-Hydrogen Transfer to Internal Alkynes: Implications for Alkyne trans-Hydrogenation. Angew. Chem., Int. Ed. 2015, 54, 12431-12436. (c) Neumann, K. T.; Klimczyk, S.; Burhardt, M. N.; Bang-Andersen, B.; Skrydstrup, T.; Lindhardt, A. T. Direct trans-Selective Ruthenium-Catalyzed Reduction of Alkynes in TwoChamber Reactors and Continuous Flow. ACS Catal. 2016, 6, 47104714. (d) Kusy, R.; Grela, K. E- and Z-Selective Transfer Semihydrogenation of Alkynes Catalyzed by Standard Ruthenium Olefin Metathesis Catalysts. Org. Lett. 2016, 18, 6196-6199.

(8) Tani, K.; Iseki, A.; Yamagata, T. Efficient transfer hydrogenation of alkynes and alkenes with methanol catalysed by hydrido(methoxo)iridium(III) complexes. Chem. Commun. 1999, 1821-1822.

(9) Srimani, D.; Diskin-Posner, Y.; Ben-David, Y.; Milstein, D. Iron pincer complex catalyzed, environmentally benign, E-selective semihydrogenation of alkynes. Angew. Chem., Int. Ed. 2013, 52, 1413114134.

(10) (a) Barrios-Francisco, R.; García, J. Semihydrogenation of alkynes in the presence of $\mathrm{Ni}(0)$ catalyst using ammonia-borane and sodium borohydride as hydrogen sources. Appl. Catal., A 2010, 385, 108-113. (b) Richmond, E.; Moran, J. Ligand Control of $E / Z$
Selectivity in Nickel-Catalyzed Transfer Hydrogenative Alkyne Semireduction. J. Org. Chem. 2015, 80, 6922-6929.

(11) (a) Fu, S.; Chen, N.-Y.; Liu, X.; Shao, Z.; Luo, S.-P.; Liu, Q. Ligand-Controlled Cobalt-Catalyzed Transfer Hydrogenation of Alkynes: Stereodivergent Synthesis of Z- and E-Alkenes. J. Am. Chem. Soc. 2016, 138, 8588-8594. (b) Tokmic, K.; Fout, A. R. Alkyne Semihydrogenation with a Well-Defined Nonclassical $\mathrm{Co}-\mathrm{H}_{2}$ Catalyst: $\mathrm{A} \mathrm{H}_{2}$ Spin on Isomerization and E-Selectivity. J. Am. Chem. Soc. 2016, 138, 13700-13705. (c) Chen, C.; Huang, Y.; Zhang, Z.; Dong, X.-Q.; Zhang, X. Cobalt-Catalyzed ( $Z$ )-Selective semihydrogenation of alkynes with molecular hydrogen. Chem. Commun. 2017, 53, 4612-4615.

(12) (a) Pape, F.; Thiel, N. O.; Teichert, J. F. Z-Selective Copper(I)Catalyzed Alkyne Semihydrogenation with Tethered $\mathrm{Cu}$-Alkoxide Complexes. Chem. - Eur. J. 2015, 21, 15934-15938. (b) Korytiaková, E.; Thiel, N. O.; Pape, F.; Teichert, J. F. Copper(I)-Catalyzed Transfer Hydrogenations with Ammonia Borane. Chem. Commun. 2017, 53, $732-735$.

(13) For seminal examples on manganese-catalyzed hydrogenation see: (a) Elangovan, S.; Topf, C.; Fischer, S.; Jiao, H.; Spannenberg, A.; Baumann, W.; Ludwig, R.; Junge, K.; Beller, M. Selective Catalytic Hydrogenations of Nitriles, Ketones, and Aldehydes by Well-Defined Manganese Pincer Complexes. J. Am. Chem. Soc. 2016, 138, 88098814. (b) Kallmeier, F.; Irrgang, T.; Dietel, T.; Kempe, R. Highly Active and Selective Manganese $\mathrm{C}=\mathrm{O}$ Bond Hydrogenation Catalysts: The Importance of the Multidentate Ligand, the Ancillary Ligands, and the Oxidation State. Angew. Chem., Int. Ed. 2016, 55, 11806-11809. (c) Elangovan, S.; Garbe, M.; Jiao, H.; Spannenberg, A.; Junge, K.; Beller, M. Hydrogenation of Esters to Alcohols Catalyzed by Defined Manganese Pincer Complexes. Angew. Chem., Int. Ed. 2016, 55, 15364-15368. (d) Papa, V.; Cabrero-Antonino, J. R.; Alberico, E.; Spanneberg, A.; Junge, K.; Junge, H.; Beller, M. Efficient and Selective Hydrogenation of Amides to Alcohols and Amines using a Well-Defined Manganese-PNN Pincer Complex. Chem. Sci. 2017, 8, 3576-3585. (e) Espinosa-Jalapa, N. A.; Nerush, A.; Shimon, L. J. W.; Leitus, G.; Avram, L.; Ben-David, Y.; Milstein, D. Manganese-Catalyzed Hydrogenation of Esters to Alcohols. Chem. Eur. J. 2017, 23, 5934-5938. (f) van Putten, R; Uslamin, E. A.; Garbe, M.; Liu, C.; Gonzalez-de-Castro, A.; Lutz, M.; Junge, K.; Hensen, E. J. M.; Beller, M.; Lefort, L.; Pidko, E. A. Non-Pincer-Type Manganese Complexes as Efficient Catalysts for the Hydrogenation of Esters. Angew. Chem., Int. Ed. 2017, 56, 7531-7534.

(14) Commercially available from several providers with reasonable price, e.g., \$75/50 g from Shanghai Forxine Pharmaceutical Company.

(15) Kabir, M. K.; Kawahara, M.; Kumagai, H.; Adachi, K.; Kawata, S.; Ishii, T.; Kitagawa, S. The Rational Syntheses of ManganeseChloranilate Compounds: Crystal Structures and Magnetic Properties. Polyhedron 2001, 20, 1417-1422.

(16) (a) Chiriac, R.; Toche, F.; Demirci, U. B.; Krol, O.; Miele, P. Ammonia Borane Decomposition in the Presence of Cobalt Halides. Int. J. Hydrogen Energy 2011, 36, 12955-12964. (b) Benzouaa, R.; Demirci, U. B.; Chiriac, F.; Toche, P.; Miele, P. Metal Chloride-Doped Ammonia Borane Thermolysis: Positive Effect on Induction Period as well as Hydrogen and Borazine Release. Thermochim. Acta 2010, 509, 81-86. (c) Semproni, S. P.; Milsmann, C.; Chirik, P. J. FourCoordinate Cobalt Pincer Complexes: Electronic Structure Studies and Ligand Modification by Homolytic and Heterolytic Pathways. J. Am. Chem. Soc. 2014, 136, 9211-9224. (d) Srimani, D.; Mukherjee, A.; Goldberg, A. F. G.; Leitus, G.; Diskin-Posner, Y.; Shimon, L. J. W.; Ben David, Y.; Milstein, D. Cobalt-Catalyzed Hydrogenation of Esters to Alcohols: Unexpected Reactivity Trend Indicates Ester Enolate Intermediacy. Angew. Chem., Int. Ed. 2015, 54, 12357-12360.

(17) Geometries were located with the G09 package using the PBE functional together with the SVP basis set for main group atoms and the TZVP basis set for Mn. The reported free energies were obtained via single-point energy calculations using the PBEO-D3 functional and the TZVP basis set on all atoms. Solvent effects (methanol) were evaluated with the PCM model, including nonelectrostatic terms. (Full computational details can be found in the Supporting Information.) 
(18) Conradie, J.; Ghosh, A. Electronic Structure of Trigonal-Planar Transition-Metal-Imido Complexes: Spin-State Energetics, SpinDensity Profiles, and the Remarkable Performance of the OLYP Functional. J. Chem. Theory Comput. 2007, 3, 689-702.

(19) During the publication process, a related manganese-catalyzed semihydrogenation of alkynes to $(E)$-olefins has been reported, see: Zhou, Y.-P.; Mo, Z.; Luecke, M.-P.; Driess, M. Stereoselective Transfer Semi-Hydrogenation of Alkynes to E-Olefins with N-Heterocyclic Silylene-Manganese Catalysts. Chem. - Eur. J. [Online early access]. DOI: 10.1002/chem.201705745. Published Online: Dec 20, 2017.

https://onlinelibrary.wiley.com/doi/abs/10.1002/chem.201705745. 